\title{
The system of multimedia technologies implementation in high school
}

\author{
Dina Prostova ${ }^{1, *}$, Natalya Sosnina ${ }^{1}$, and Natalya Shirina ${ }^{2}$ \\ ${ }^{1}$ Ural State University of Economics, 620144 Ekaterinburg, Russia \\ ${ }^{2}$ Yaroslavl State Medical University, 150000 Yaroslavl, Russia
}

\begin{abstract}
Recent research highlights the effective use of multimedia as an auxiliary strategy; it helps to easily deliver educational material to students and plays a positive role in strengthening the overall trend towards computer use in education. It is impossible to overestimate the importance of multimedia technologies in education. Multimedia technologies help simplify abstract content, allow you to differ from individual people, and allow you to coordinate diverse views from different points of view. Of course, multimedia technologies improve teaching and learning process, but this technology has a number of drawbacks that make it difficult to implement it into the higher school program. The authors of the study developed the system of MMT implementation is the educational process in high school. The system was developed according to the content of MM phenomenon based on advantages as well as eliminated disadvantages of new technologies in learning process. The definite level of financing and technical support, provided according to the State Program on Digital Economy of the Russian Federation, allows high school to organize the learning process via MMT providing a big volume of different opportunities for specific purposes. Follow the developed system allows educating digital personnel ready to work for digital economy of the region.
\end{abstract}

\section{Introduction}

The modern economy imposes new requirements on all spheres of economic activity, which is reflected in the emergence of new forms of interaction between economic subjects and their functional load. The digital transformation triggered by the contract award provides all actors with the opportunity to achieve qualitatively new results of economic activity [1], [2].

Education as an economic activity is also undergoing a transformation in terms of the organizational forms and methods of educational work aimed at the sustainable development of the digital economy.

Currently, the following contradictions have been identified in higher education:

- Between the contract award for digitalization of education and the lack of funding for this process in the higher education context;

\footnotetext{
*Corresponding author: prostova.dina@yandex.ru
} 
- Between the needs of the digital economy for a modern digital workforce and the unpreparedness of higher education to modernize the learning process to meet the new requirements;

- Between the undeniable potential of new multimedia technologies in digital training and the low level the digital competencies of teachers have developed.

Due to this situation, many higher education institutions are moving towards using multimedia technology as an innovative teaching and learning strategy in a digital learning environment. Multimedia technology can alternatively be used as an innovative and effective tool in equipping graduates with the necessary digital skills [3].

The use of multimedia technology in education is increasing day by day. The reasons for the introduction of new multimedia technologies are to increase the output ratio and, as a consequence, to develop a graduate's mindset and outlook that is optimal for existence in today's environment.

The modernization of teaching methods requires increased use of multimedia technology in education. This approach makes it possible to create an entirely new tertiary school, which greatly increases the effectiveness of lessons and individualizes the learning process.

\subsection{Related Work}

Concepts such as "computerized society", "video civilization", "global village" are an expression of the modern multimedia era. In this era, we have a variety of resources ranging from traditional media to today's potential computer, Internet, etc., which are repositories of multimedia and materials. Again, it is said that today's education is not good enough for tomorrow. As science and technology advance, societal scenarios change very rapidly and new problems arise from time to time. As long as our learning needs are not adequately met, there will be mismatch, mis-adaptation and cultural encampment [4].

The current research in the field of multimedia technology allows it to be seen as an innovative tool that allows for qualitatively new learning outcomes. Multimedia technologies can be rightly positioned as a new stage in the development of computer-based learning technologies, as they are based on the learning capabilities of the computer and involve the use of modern programming technologies [5].

International authors point to the possibility of moving from a predominantly linear learning environment to a non-linear environment. Such technologies allow students to have a greater degree of choice, involving them in the learning process. For example, Gourav Mahajan argues that the learning environment created by new media facilitates the transformation of the role of the teacher into that of the learner and vice versa [4]. The power of multimedia lies in its ability to electrify people's thinking and active centers of consciousness with sensory elements of dazzling pictures, captivating sounds and captivating videos alongside textual material.

A team of international researchers led by M.D. Abdulrahaman links the use of multimedia technology to an understanding of the cognitive theory of multimedia learning, which postulates three assumptions describing how people learn from educational multimedia materials [6].

These hypotheses can be summarized as two-channel, bandwidth-limited and active processing. Two-channel mode assumes that learners have multiple channels to separate visual and auditory information. Limited capacity implies that there is a limit to the amount of data that can be processed in each channel. Understanding this will allow teachers to avoid overloading students with large amounts of information. On the other hand, students will be aware of the limitations or possibilities of processing the information. Active processing means that when it comes to selecting, organizing and integrating information, 
people are active agents and are able to manage the forms of information with which they interact.

Russian researchers in the application of the technologies described emphasize a clear understanding of the limits of application of multimedia technologies [5]. It is important to prevent the learning process from becoming all about entertainment and to ensure that learning is effective, as opposed to spectacular. The excessive use of multimedia technology can increase the psycho-emotional burden on learners and thereby reduce the effectiveness of learning.

A team of scholars from Crimean Federal University reveals the potential of multimedia technology in engaging the greatest number of perception channels: visual, auditory, and all sensory channels, which allows for the formation of a virtual learning environment. This should increase students' interest in the discipline studied and, as a consequence, improve the quality of knowledge [7].

Thus, multimedia technology really contributes to the efficiency of the learning process in higher education institutions, integrates its powerful educational potential and provides a favourable environment for the formation of competencies needed by future professionals.

\subsection{Purpose of the study}

The purpose of this study is aimed at finding out the problems that hinder the implementation of multimedia technologies in the learning process at high school and providing the offers to eliminate these difficulties. The tasks of the study are the following.

1. To provide different views on multimedia phenomenon at high school.

2. To determine the advantages and disadvantages of multimedia in learning process.

3. To find out the existing problems.

4. To develop the system of multimedia implementation at high school.

5. To formulate some offers on the multimedia usage.

\subsection{Research Methods}

The authors applied systematic methods of analysis of the information researched. The found matters developed the direction of the study. The authors modelled the process of MM implementation in high school based on the example of Ural State University of Economics.

\section{Background}

Computer-information technologies and multimedia provide the teacher with the opportunity to quickly share a variety of applications tools that promote more effective and informed learning of the learning material, and save class time by filling it with information. The introduction of information multimedia technologies turns an ordinary learning process into a more technological and effective learning process, which helps to increase the interest in learning among students. When using multimedia technologies in classroom through the use of interactive elements, structuring and visualizing information, there is an increase in students' motivation, activation of their cognitive activity, both at the conscious level and at the subconscious level [7].

\subsection{Multimedia Phenomenon}


Multimedia technologies (MMT) are the result of the convergence of multiplex technologies such as audiovisual, computing, and communication. They are designed to convey information to the general public. As with other media, the achievement of goals depends largely on the quality of communication between the technology and the end users [8]. Getting the information is a voluntary decision, and the user can easily opt out of MMT with low interest.

Traditionally, computer system specifications focus on functional requirements expressed by customers and end users. When the purpose is to transmit information, users cannot easily decide on the content of the application, and therefore there is a need for expert intervention to decide what information should be contained in the system [9], [10].

The development of multimedia technologies is an expensive process in terms of the labor, hardware, and software and multimedia resources spent on it. This fact requires funds that can help protect and disseminate these investments, mainly various types of multimedia and related description data. In computer science, database systems are approved tools for making data and conceptual knowledge stored in a central pool available to various users and applications. In the case of multimedia technologies, there are many new implications arising from the characteristic properties of multimedia that need to be considered in order to apply the traditional methods of database systems to the much more complex field of multimedia database systems.

There are several points of view on the study of the phenomenon of multimedia. First of all, there are various physical media (graphics, images, sound, etc.) that define the main characteristics of multimedia. But there are also various fields, such as computer graphics, image processing, and synthetic sound composition that are involved in the creation, processing, and transformation of multimedia objects [11] (Fig 1).

Many multimedia systems are better described as systems for presenting information rather than processing information. The data stored in such systems does not change while the system is running, so this means that many notations that have traditionally been used to model data processing requirements, such as data flow diagrams or entity life histories, will be irrelevant. Problems of this kind are not unique to the development of multi-user systems, but are likely to have a greater impact on the development process than in traditional systems [12].

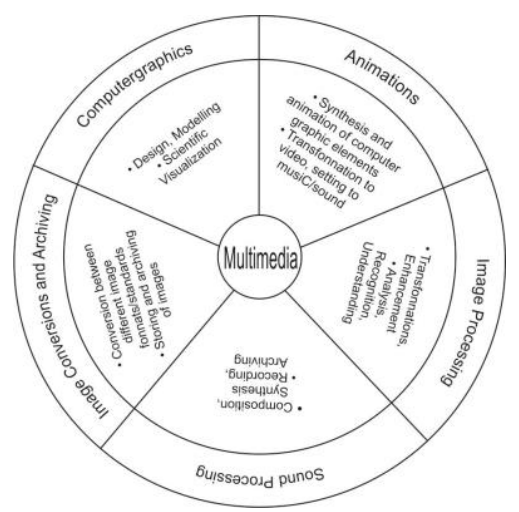

Fig. 1. Multimedia System

Summarizing the above concepts, in the context of this study, multimedia technologies will be understood as the interaction of visual and audiovisual effects under the control of interactive software using modern technical and software tools in a single digital representation. 


\subsection{Multimedia Classification}

There are different approaches to classifying MMT. Modern computer science knows two categories of multimedia based on the form of presentation - linear and non-linear. Linear multimedia tools usually move from one screen to another and are usually used by teachers as an additional teaching tool. This form of multimedia tends to limit learning potential, as it does not require active participation.

Non-linear multimedia tools (those that include hyperlinks) offer viewers interactivity, control over progress, and choice in building knowledge. When used as active learning tools, non-linear multimedia engages students in the use of 21 st-century skills, which fall into six different categories, i.e. critical thinking, information and media literacy, creativity, communication skills, collaboration, and contextual learning. Non-linear multimedia also provides a variety of opportunities for creative reflection on the digital age [4].

For educational purposes, scientists distinguish three MMTS: for educational purposes, for education and entertainment at the same time (Edutainment), for entertainment. Edutainment has great developmental abilities, especially in early childhood, as the accelerated acquisition and processing of new information increases the productivity of the brain [5].

\section{The analysis of multimedia implementation in high school}

Recent research highlights the effective use of multimedia as an auxiliary strategy; it helps to easily deliver educational material to students and plays a positive role in strengthening the overall trend towards computer use in education. Multimedia has a positive impact on cognitive and academic achievement, understanding, and application [13]. The possibilities of using multimedia technologies in higher education are characterized by obvious advantages [6] (Fig.2).

Multimedia educational technologies are, at a minimum, the active use of Internet resources, which will not surprise anyone, and, at a maximum, the possibility of creating an individualized, entertaining, effective and remote learning process that will actively develop the overall intellectual potential of humanity.

However, despite all the advantages, foreign and domestic authors agree on the existing shortcomings in the application of MMT, knowledge of which will help to level out the difficulties associated with the introduction of MMT in the learning process (Fig.2).

The authors of the study developed the system of MMT implementation is the educational process in high school. The system was developed according to the content of MM phenomenon based on advantages as well as eliminated disadvantages of new technologies in learning process. The definite level of financing and technical support, provided according to the State Program on Digital Economy of the Russian Federation, allows high school to organize the learning process via MMT providing a big volume of different opportunities for specific purposes. Follow the developed system allows educating digital personnel ready to work for digital economy of the region. 


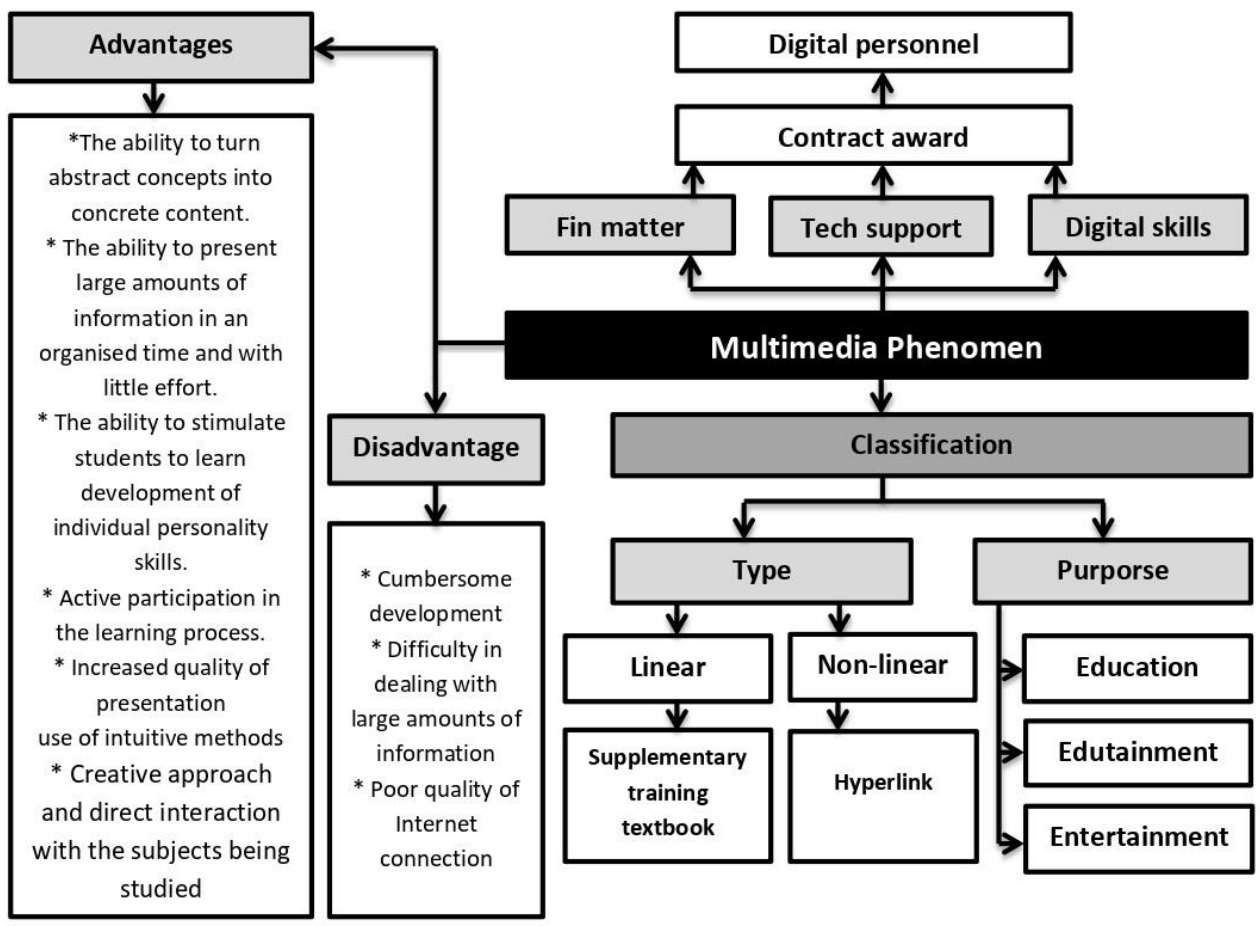

Fig. 2. Multimedia System in High School

\section{Conclusion}

It is impossible to overestimate the importance of multimedia technologies in education. Multimedia technologies help simplify abstract content, allow you to differ from individual people, and allow you to coordinate diverse views from different points of view. Of course, multimedia technologies improve teaching and learning process, but this technology has a number of drawbacks that make it difficult to implement it into the higher school program.

The system of multimedia technologies implementation in the learning process developed by the authors reflects their deep potential, helps to level the difficulties associated with their implementation and ensures the smooth development of this system in accordance with the needs of the digital economy.

\section{References}

1. The program "Digital Economy of the Russian Federation", approved by the Government of the Russian Federation dated July 28, 2017 No. 1632-r, http://static.government.ru/

2. D.M. Prostova, A.D. Tikhonova, N.G. Sosnina, Proceedings of ISCDE, 443 (2019)

3. N. Mai, T.K. Ken Neo, ET \& S, 4(4), 19 (2001)

4. M. Gourav, JoE \& P, 3(1) (2012)

5. O.V. Bondarenko, Modern problems of science and education, 3 (2017), http://scienceeducation.ru/ 
6. M.D. Abdulrahaman, N. Farukb, A.A. Oloyede, N.T. Surajudeen-Bakinde, L.A. Olawoyin, O.V. Mejabi, Y.O. Imam-Fulani, A.O. Fahm, A.L. Azeeze, Hel, 6(11) (2020)

7. V. Taran, A. Karakhanyan, Bull.oS\&P, 5(6) (2019)

8. S. Levy, F. Gamboa, JoSE\&A, 6, 416 (2013)

9. S. Jones and C. Britton, Early Elicitation and Definition of Requirements for an Interactive Multimedia Informa- tion System, IEEE Proceedings of ICRE, 12 (1996)

10. F. Anthony, Writing for Visual Media, FP, W, (2006).

11. M. Rhiner, P. Stucki, Multimedia, 269 (1992)

12. C. Britton, S. Jones, M. Myers, M. Sharif, . UHCSTR, UofH, 244 (1996)

13. S. Aloraini, JoKSU - L\&T, 4(2), 75 (2012) 